\title{
Diversity of Frankia in root nodules of six Morella sp. from the Cape flora of South Africa
}

\author{
Dale A. Wilcox ${ }^{*}$, Don A. Cowan ${ }^{\#}$ \\ *Institute for Microbial Biotechnology and Metagenomics, Department of \\ Biotechnology, University of the Western Cape, Cape Town 7535, South Africa \\ ${ }^{\#}$ Centre for Microbial Ecology and Genomics, University of Pretoria, Pretoria \\ 0002, South Africa
}

\author{
Corresponding Author: \\ Don A. Cowan, \\ e-mail: don.cowan@up.ac.za \\ tel: +27 (0)12 4205873
}

\section{Abstract}

Africa hosts numerous endemic actinorhizal plants from the genus Morella, but the diversity of their Frankia endosymbionts has never been explored. The diversity of Frankia in root nodules collected from natural stands of six Morella species within the Cape flora of South Africa was investigated. The diversity of Frankia in root nodules collected from natural stands of six Morella species within the Cape flora of South Africa was investigated by comparative nitrogenase (nifH) gene sequence analysis. Gene sequences assigned nodular strains to both cluster I (Alnus hostinfection group) and cluster III (Elaeagnus host-infection group), with sequences from both groups recovered from three hosts: $M$. intergra, M. diversifolia and $M$. quercifolia. Cluster I sequences were found in nodules from acidic soils exclusively. Frankia strains representing both groups were isolated and characterized by $16 \mathrm{~S}$ rRNA and nif $\mathrm{H}$ analysis. This study is the first to investigate the diversity of Frankia associated with endemic African actinorhizal species in their natural habitats, and to report isolation of Frankia strains from African Morella.

Morella, Frankia, actinorhizal symbiosis, Cape flora, nitrogenase, nifH 


\section{Introduction}

Frankia are geographically widespread gram-positive soil actinomycetes capable of entering into nitrogen fixing symbioses with more than 200 specific host plants from several genera distributed across eight families, in what are known as "actinorhizal" symbioses (Benson et al. 2004; Normand et al. 2014). Host plants, which occur on all continents except Antarctica, benefit from this association by gaining the ability to colonize marginal soils and are often pioneer species at newly formed or exposed sites (Benson et al 2004; Benson and Dawson 2007).

Because of their unusual ability to effectively nodulate with strains from both clusters I and III, alternatively referred to as the Alnus-, and Elaeagnus- $\underline{H}$ ost Infection Groups (HIGs), when inoculated under laboratory conditions, the genus Morella (a member of the Myricaceae, along with actinorhizal Myrica and Comptonia) is considered promiscuous (Vandenbosch and Torrey 1983; Torrey 1990; Maggia and Bousquet 1994; Huguet et al. 2005). Although the symbiotic preferences of comparatively few Morella species have been studied under natural field conditions, host/endophyte associations have typically been found to be more specific than those found when hosts are greenhouse-grown, and it is thought that this may be a consequence of prevalent edaphic conditions. Whether this is due to the availability of infectious strains or the effect of soil conditions on either strain infectivity or host preference is unknown (Zimpfer et al. 1999; Clawson et al. 1999; Clawson and Benson 1999; Huguet et al. 2001; He et al. 2004; Huguet et al. 2005).

The African continent hosts an abundance of actinorhizal species, principally Morella (previously Myrica), of which there are 30 species (approximately half of the global total (Gtari et al. 2004; Huguet et al. 2005; The Plant List, Version 1.12014 ). Furthermore, Morella is the only actinorhizal genus indigenous to southern Africa. Despite this, within Africa endemic actinorhizal plants and their microsymbionts have been largely neglected, especially in the south of the continent (Gtari and Dawson 2011). The Cape Region of South Africa, an area of only 90000 square kilometers but with remarkable floral richness (Goldblatt 1978), is home to seven Morella species of which three are endemic (Killick et al. 1998; Goldblatt and Manning 2000; Gtari and Dawson 2011).

Morella from the Cape region vary widely in both their morphology and ecology, and most are easily identifiable in the field (Killick 1969; Killick et al. 1998; Herbert 2005). Species occupy a number of varied habitats (Goldblatt and Manning 2000); Morella cordifolia and M. quercifolia are lowland species, the former stabilizing coastal dunes in a role similar to that of the North American M. cerifera while the latter inhabits coastal flats, marshes and wetlands. Perennial stream and river banks may be colonized by $M$. integra or M. serrata, both of which are small trees. M. kraussiana 
occurs on the mountains of the Western Cape Province, where it has access to moisture from perennial cloud cover during the region's drought prone summers. M. diversifolia, a possible hybrid of M. kraussiana and M. quercifolia (Bond 1971), occupies the same niche as M. kraussiana, but is restricted to the mountains of the Cape peninsula (Helme and Trinder-Smith 2006). Despite uncertainty over the classification of the Myricaceae elsewhere in the world (Herbert 2005), all of the Cape Morella are accepted species (The Plant List, Version 1.1 2015).

Early investigations found all southern African Morella to be nodule-bearing, demonstrated that the nodules were the site of nitrogen fixation and considerably expanded the number of plants from the Myricaceae known to be actinorhizal (Van Ryssen and Grobbelaar 1970; Bond 1971; Bond 1976). Beyond these investigations the subject of endophyte diversity in southern African actinorhizal hosts was not pursued, partly because Frankia strains had not yet been isolated (Callaham et al. 1978).

In this study we investigated the diversity of nodular Frankia associated with six African Morella species growing in their natural environments using partial nif $\mathrm{H}$ sequences amplified directly from root nodules. Additionally, endemic southern African Frankia strains were isolated from four hosts and classified using nif $\mathrm{H}$ and 16S rDNA Frankia sequences from nucleotide databases.

\section{Methods}

\section{Nodule collection and processing}

Root nodules were collected from six southern African Morella species ( $M$. cordifolia, M. diversifolia, M. quercifolia, M. integra, M. serrata and M. kraussiana) from naturally occurring stands throughout the Western Cape province of South Africa, at sites indicated in Table 1 and Figure 1, between April of 2012 and December of $2013^{1}$. Of these species, M. diversifolia, M. integra and M. kraussiana are endemic to the Cape flora (Goldblatt and Manning 2000). Nodules were stored on ice or in habitat soil during transport to the laboratory, whereupon they were processed immediately. Individual nodules were cleaned of adherent soil particles by washing under a stream of water. Subsequent to this a single lobe was removed from each nodule, washed in sterile distilled water, carefully cleaned under a dissecting microscope and washed twice more. Lobes were then surface-sterilized in $30 \% \mathrm{H} 2 \mathrm{O} 2$

${ }^{1}$ Species occurrence data may be conveniently viewed using the South African National Biodiversity Institute Integrated Biodiversity Information System (SIBIS) 
Table 1: Details of Morella species occurrence, with samples collection within $100 \mathrm{~m}$ of indicated coordinates for each site (Figure 1). The identity of the species found at site B2 is uncertain and may have been either M. kraussiana or M. diversifolia. For the purposes of this study we considered them the latter.

\begin{tabular}{|c|c|c|c|c|c|c|}
\hline Species & Site & Latitude & Longitude & $\mathrm{pH}\left(\mathrm{CaCl}_{2}\right)^{1}$ & $\mathrm{Nod}^{2}$ & $\mathrm{HIG}^{3}$ \\
\hline \multirow[t]{9}{*}{ M. cordifolia } & A 1.1 & $33^{\circ} 11^{\prime} 33.40^{\prime \prime} \mathrm{S}$ & $18^{\circ} 4^{\prime} 19.00^{\prime \prime} \mathrm{E}$ & $8.31(0.07)$ & 2 & III \\
\hline & A 1.2 & $33^{\circ} 11^{\prime} 51.70^{\prime \prime} \mathrm{S}$ & $18^{\circ} 4^{\prime} 41.80^{\prime \prime} \mathrm{E}$ & $8.43(0.13)$ & 4 & III \\
\hline & A 1.3 & $33^{\circ} 8^{\prime} 28.40^{\prime \prime} \mathrm{S}$ & $18^{\circ} 6^{\prime} 12.90^{\prime \prime} \mathrm{E}$ & ND & 1 & III \\
\hline & A 1.4 & $33^{\circ} 14^{\prime} 41.00^{\prime \prime} \mathrm{S}$ & $18^{\circ} 11^{\prime} 32.40^{\prime \prime} \mathrm{E}$ & ND & 2 & III \\
\hline & A 1.5 & $33^{\circ} 13^{\prime} 40.00^{\prime \prime} \mathrm{S}$ & $18^{\circ} 9^{\prime} 19.30^{\prime \prime} \mathrm{E}$ & $7.70(0.24)$ & 4 & III \\
\hline & A 2 & $33^{\circ} 45^{\prime} 14.49^{\prime \prime} \mathrm{S}$ & $18^{\circ} 26^{\prime} 31.70^{\prime \prime} \mathrm{E}$ & ND & 1 & III \\
\hline & A 4 & $34^{\circ} 23^{\prime} 20.00^{\prime \prime} \mathrm{S}$ & $21^{\circ} 25^{\prime} 29.14^{\prime \prime} \mathrm{E}$ & $8.16(0.02)$ & 8 & III \\
\hline & B 4 & $34^{\circ} 4^{\prime} 54.50^{\prime \prime} \mathrm{S}$ & $18^{\circ} 27^{\prime} 59.00^{\prime \prime} \mathrm{E}$ & $8.16(0.02)$ & 36 & III \\
\hline & B 7 & $34^{\circ} 21^{\prime} 27.70^{\prime \prime} \mathrm{S}$ & $18^{\circ} 55^{\prime} 28.00^{\prime \prime} \mathrm{E}$ & $7.06(0.17)$ & 10 & III \\
\hline \multirow[t]{4}{*}{ M. quercifolia } & A 1.5 & $33^{\circ} 13^{\prime} 40.00$ "S & $18^{\circ} 9^{\prime} 19.30^{\prime \prime} \mathrm{E}$ & $7.70(0.24)$ & 15 & III \\
\hline & В 1.1 & $34^{\circ} 13^{\prime} 59.90^{\prime \prime} \mathrm{S}$ & $18^{\circ} 22^{\prime} 51.10^{\prime \prime} \mathrm{E}$ & ND & 2 & III \\
\hline & B 3 & $34^{\circ} 5^{\prime} 31.30^{\prime \prime} \mathrm{S}$ & $18^{\circ} 25^{\prime} 30.80^{\prime \prime} \mathrm{E}$ & ND & 1 & I \\
\hline & B 5 & $33^{\circ} 56^{\prime} 11.00^{\prime \prime} \mathrm{S}$ & $18^{\circ} 37^{\prime} 7.90^{\prime \prime} \mathrm{E}$ & $7.45(0.07)$ & 21 & III \\
\hline \multirow[t]{2}{*}{ M. diversifolia } & B 2 & $33^{\circ} 58^{\prime} 16.90^{\prime \prime} \mathrm{S}$ & $18^{\circ} 25^{\prime} 15.20^{\prime \prime} \mathrm{E}$ & $3.45(0.01)$ & 18 & III \\
\hline & В 1.2 & $34^{\circ} 13^{\prime} 13.60^{\prime \prime} \mathrm{S}$ & $18^{\circ} 22^{\prime} 49.70^{\prime \prime} \mathrm{E}$ & $4.48(0.03)$ & 13 & I/III \\
\hline \multirow[t]{3}{*}{ M. kraussiana } & B 1.3 & $34^{\circ} 13^{\prime} 10.70^{\prime \prime} \mathrm{S}$ & $18^{\circ} 22^{\prime} 46.00^{\prime \prime} \mathrm{E}$ & $4.46(0.02)$ & 2 & I \\
\hline & В 3.1 & $34^{\circ} 5^{\prime} 33.80^{\prime \prime} \mathrm{S}$ & $18^{\circ} 25^{\prime} 35.60^{\prime \prime} \mathrm{E}$ & ND & 1 & I \\
\hline & B 3.2 & $34^{\circ} 5^{\prime} 34.60^{\prime \prime} \mathrm{S}$ & $18^{\circ} 25^{\prime} 59.60^{\prime \prime} \mathrm{E}$ & $4.48(0.03)$ & 3 & I \\
\hline M. serrata & B 6 & $33^{\circ} 58^{\prime} 23.20^{\prime \prime} \mathrm{S}$ & $18^{\circ} 56^{\prime} 13.40^{\prime \prime} \mathrm{E}$ & $5.21(0.08)$ & 6 & I \\
\hline \multirow[t]{4}{*}{ M. integra } & A 3 & $32^{\circ} 6{ }^{\prime} 55.00^{\prime \prime} \mathrm{S}$ & $19^{\circ} 3^{\prime} 54.30^{\prime \prime} \mathrm{E}$ & $4.17(0.06)$ & 18 & I/III \\
\hline & A 3.1 & $32^{\circ} 6^{\prime} 6.80^{\prime \prime} \mathrm{S}$ & $19^{\circ} 4^{\prime} 3.10^{\prime \prime} \mathrm{E}$ & $3.83(0.07)$ & 3 & III \\
\hline & A 3.2 & $32^{\circ} 6^{\prime} 10.60^{\prime \prime} \mathrm{S}$ & $19^{\circ} 3^{\prime} 52.80^{\prime \prime} \mathrm{E}$ & $4.04(0.02)$ & 8 & I \\
\hline & A 3.3 & $32^{\circ} 21^{\prime} 41.25^{\prime \prime} \mathrm{S}$ & $19^{\circ} 4^{\prime} 19.52^{\prime \prime} \mathrm{E}$ & ND & 23 & I \\
\hline
\end{tabular}

${ }^{1}$ Soil $\mathrm{pH}$, mean of readings from three samples with standard deviation in parentheses.

${ }^{2}$ Number of nodules collected per locality for which nifH amplification was successful.

${ }^{3}$ Frankia host infection groups found in nodules at each site.
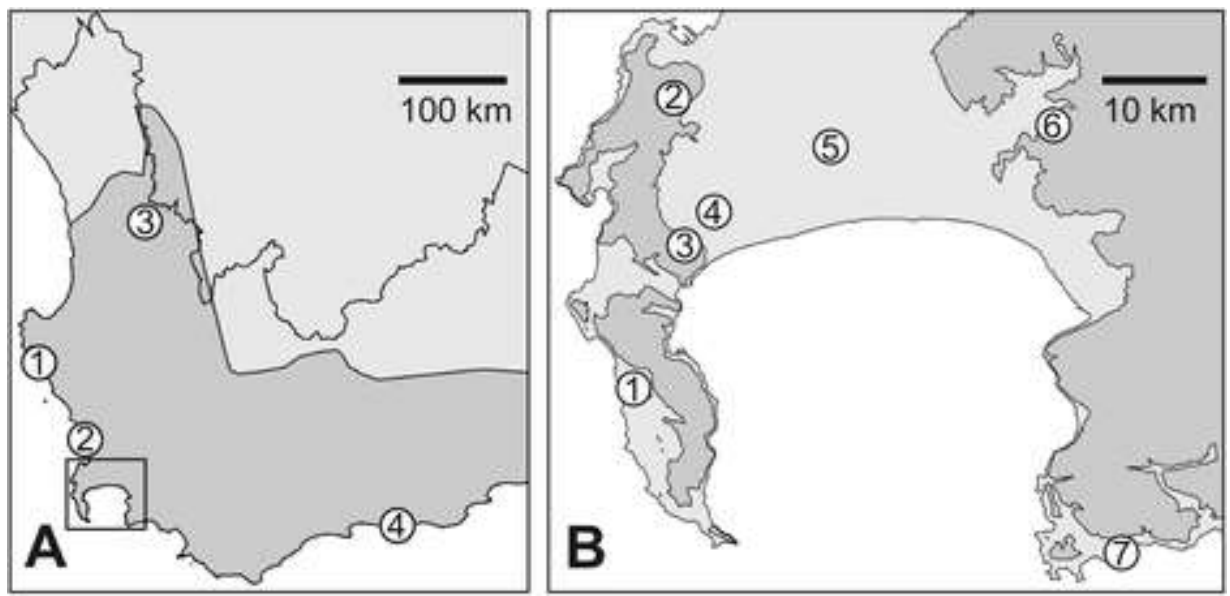

Figure 1: Map of Morella sampling locations within the Western Cape Province of South Africa, with the Cape Floristic Region indicated in dark grey (panel A). Site A1 is West Coast National Park, site A2 is the Blouberg Provincial Nature Reserve, site A3 is the Cedeberg wilderness area, site A4 is the Stilbaai Nature Reserve. The Cape peninsula and greater False Bay area are indicated by the boxed inset (panel B). Areas at altitudes above 100m are indicated in dark grey and correspond to the Table Mountain range on the Cape Peninsula in the West, and the Boland mountain range in the East. 
Sites B1-B3 are within Table Mountain National Park and correspond to sampling sites on the Bonteberg, Table Mountain and the Steenberg respectively. Sites B4-B6 are the Zandvlei, Cape Flats and Jonkershoek nature reserves. Site B7 is a beach near the Kogelberg Nature Reserve. GPS coordinates and Morella root nodules collected at each site are detailed in Table 1.

for 30 min with periodic manual agitation, after which they were rinsed copiously with sterile distilled water.

For Frankia isolation two approaches were used: firstly, sterilized lobes were sectioned and incubated in $6 \mathrm{ml}$ of DPM or FDM medium without a fixed nitrogen source and supplemented with cyclohexamide $\left(50 \mu \mathrm{g} \mathrm{mL}^{-1}\right)$, nalidixic acid (10 $\mu \mathrm{g} \mathrm{mL}^{-1}$ ) and sodium azide $\left(5 \mu \mathrm{g} \mathrm{mL}^{-1}\right.$ ) (Meesters et al. 1985; Lechevalier and Lechevalier 1990). For Morella species in which this first technique failed to produce isolates a second method was attempted. Lobe sections were incubated on similarlyformulated gellan gum-based solid media, both with and without ammonium chloride (Bass and Benson 2007). Plates and tubes were incubated in the dark at $28^{\circ} \mathrm{C}$ until colony outgrowth from nodule surfaces was observed. Filamentous outgrowths were excised under a dissecting microscope, homogenized in $1 \mathrm{~mL}$ of sterile $\mathrm{dH} 2 \mathrm{O}$ and the suspension plated out on gellan gum-based Frankia medium containing pyruvate $\left(1.2 \mathrm{~g} \mathrm{~L}^{-1}\right)$ and peptone $\left(1.2 \mathrm{~g} \mathrm{~L}^{-1}\right)$. Plates were sealed with parafilm and incubated in the dark at $28^{\circ} \mathrm{C}$ for three weeks. Single colonies were then excised, processed as described above, and re-plated. This exercise was repeated a minimum of four times for each isolate.

Nucleic acids were extracted from nodule lobes, which were prepared in the same manner as those used for strain isolation, and Frankia isolates using a MoBio PowerPlant Pro kit (MoBio, Carlsbad, CA) according to the manufacturer's instructions.

\section{Soil pH determination}

Soil $\mathrm{pH}$ was determined as previously described (Schofield and Wormald Taylor 1955). Measurements were taken in triplicate on individually prepared 1:5 suspensions of soil in $0.01 \mathrm{~N} \mathrm{CaCl} 2$ and distilled water.

\section{PCR conditions and molecular identification}

Sequencing of nif $\mathrm{H}$ gene fragments from nodule extracts and Frankia isolates were performed in both directions using primers and nifHr (Welsh et al. 2009a). Each 25 $\mu \mathrm{L}$ reaction contained $2 \mu \mathrm{L}$ dNTPs $(2.5 \mathrm{mM}$ each), $2.5 \mu \mathrm{L} 10 \times$ PCR buffer, $1 \mu \mathrm{L}$ of each primer $(0.1 \mu \mathrm{M}) 0.65 \mu \mathrm{L}$ DMSO, $1.25 \mu \mathrm{L}$ BSA $\left(10 \mu \mathrm{g} \mathrm{mL}^{-1}\right), 0.1 \mu \mathrm{L}$ ExTaq ( $5 U \mu \mathrm{L}^{-1}$; TaKaRa) and $1 \mu \mathrm{L}$ of template. PCR conditions were $95^{\circ} \mathrm{C}$ for 5 $\min ; 35$ cycles of $94^{\circ} \mathrm{C}$ for $30 \mathrm{~s}, 60^{\circ} \mathrm{C}$ for $30 \mathrm{~s}, 72^{\circ} \mathrm{C}$ for $45 \mathrm{~s}$; and $72^{\circ} \mathrm{C}$ for $5 \mathrm{~min}$.

Partial 16S rRNA genes from Frankia isolates were amplified using primers FGPS1509'-153 and FGPS-281 bis (Normand et al. 1996). Each $50 \mu L$ reaction contained 
$4 \mu \mathrm{L}$ dNTPs (2.5 mM each), $5 \mu \mathrm{L} 10 \times$ PCR buffer, $2 \mu \mathrm{L}$ of each primer $(0.1 \mu \mathrm{M}) 1.3$ $\mu \mathrm{L}$ DMSO, $3 \mu \mathrm{L} \mathrm{BSA}\left(10 \mu \mathrm{g} \mathrm{mL}^{-1}\right), 0.2 \mu \mathrm{L}$ ExTaq $\left(5 \mathrm{U} \mu \mathrm{L}^{-1}\right.$; TaKaRa) and $1 \mu \mathrm{L}$ of template. PCR conditions were $95^{\circ} \mathrm{C}$ for $5 \mathrm{~min} ; 35$ cycles of $94^{\circ} \mathrm{C}$ for 1 $\min , 60^{\circ} \mathrm{C}$ for $1 \mathrm{~min}, 72^{\circ} \mathrm{C}$ for $2 \mathrm{~min}$; and $72^{\circ} \mathrm{C}$ for $5 \mathrm{~min}$. All reactions were carried out in an automated thermal cycler (T100, Bio-Rad) and amplification products visualized on $1 \%$ agarose gels. Amplified nif $\mathrm{H}$ and $16 \mathrm{~S}$ rRNA gene fragments were purified with ExoSAP-IT PCR cleanup reagent (USB Corp., Cleveland, OH, USA) by combining $5 \mu \mathrm{L}$ PCR product with $0.25 \mu \mathrm{L}$ of reagent in a final reaction volume of 7 $\mu \mathrm{L}$ and incubating at $37^{\circ} \mathrm{C}$ for $45 \mathrm{~min}$, followed by $80^{\circ} \mathrm{C}$ for $15 \mathrm{~min}$. Sequencing was performed at the Stellenbosch University Central Analytical Facility using the primers used in their generation, and with the addition of internal sequencing primers $\mathrm{F} 2\left(5^{t}\right.$-ACT CCT ACG GGA GGC AGC AG) and R2 $\left(5^{t}\right.$-GGA CTA CCI GGG TAT CTA ATC C) in the case of the 16S rRNA gene. Chromatograms were visually assessed, corrected by hand where necessary, and assembled in CLC Main Workbench (version 6.2.1). Representatives of each unique sequence were deposited in GenBank under accession numbers KP342075-KP342100 (nodulederived $n i f \mathrm{H}$ ), KP342111-KP342120 (isolate-derived $n i f \mathrm{H}$ ) and KP342101-KP342110 (isolate $16 \mathrm{~S}$ rRNA).

\section{Phylogenetic analysis}

Non-identical 606 bp partial nifH sequences (hereafter referred to as Cape Frankia Nitrogenase, or CFN) were identified by nucleotide BLAST analysis and grouped into operational taxonomic units (OTUs) using the average-neighbor algorithm in MOTHUR (version 1.32.0). Additionally, sequences were grouped at $\geq 99 \%$, $\geq 98 \%$, $\geq 96 \%, \geq 94 \%, \geq 93 \%$ and $\geq 92 \%$ similarity levels. Non-identical nifH amplification fragments from Cape Morella nodules and isolates were aligned with Frankia nifH sequences downloaded from public databases, using CLC Main Workbench (version 6.2.1). The final data set comprised 26 sequences from Cape Morella nodules and 250 database sequences (75 from pure cultures and 175 obtained from nodules) representing previously defined clusters KL1-KL5 (Higgins and Kennedy 2012), KL6-KL8 (Kennedy et al. 2010) and clusters EI-EIV and AI-AV (Welsh et al. 2009a). The alignment was trimmed to $512 \mathrm{bp}$, corresponding to positions 227 to 738 of the Frankia ACN14a nifH gene (NC008278), sequences grouped into OTUs with MOTHUR (version 1.32.0) as described above, and identical sequences removed. Following this, the data set was further reduced by retaining only the most divergent sequences and sequences most similar to each CFN within each of the clusters recovered at $97 \%$ similarity.

The resultant 94 sequence data set was analyzed using neighbor joining (NJ), maximum parsimony (MP), maximum likelihood (ML) and Bayesian methods as previously described (Welsh et al 2009a). Neighbor joining was completed in PAUP 
(version 4.0b) (Swofford 2003). A GTR $+\mathrm{I}+\mathrm{G}$ model of sequence evolution and set values for the proportion of invariant sites (0.5250) and gamma shape parameter (0.4060) were estimated in jModeltest (version 2.1.4) (Guindon and Gascuel 2003; Darriba et al. 2012). Settings for jModeltest2 included 11 substitution schemes, 88 candidate models, rate variation $\mathrm{I}+\mathrm{G}, \mathrm{nCat}=4$, an $\mathrm{ML}$ optimized base tree for likelihood calculation, and tree topology best of NNI and SPR. ML analysis was completed using the RAxML-HPC2 program on the CIPRES computer cluster (www.phylo.org) (Stamatakis 2006; Miller et al. 2010). Settings included GTR+CAT rate heterogeneity approximation, a proportion of invariant sites, empirical base frequencies and the number of bootstrap replicates required estimated during the run. MP analysis was completed with PAUP with 10000 random addition replicates, TBR and the multrees option set to "no" (Swofford 2003). Bootstrapping included 10000 replicates and a full heuristic search. Bayesian analysis was carried out using MRBAYES (version 3.2.2) on the CIPRES computer cluster (www.phylo.org) and included MCMC sampling, a GTR $+\mathrm{I}+\mathrm{G}$ model estimated during the run and 5 million generations with sampling every 1000 trees. A 50\% consensus tree was created with the first $25 \%$ of trees removed as burn-in. Support measures from each method were mapped onto a NJ tree using Dendropy (Sukumaran and Holder 2010) and displayed in Figtree version 1.4 (Rambaut 2009).

16S rRNA amplification products from Cape Frankia isolates were aligned with those of 34 strains retrieved from public databases and trimmed to $1380 \mathrm{bp}$. Sequences were checked for the presence of chimeras using DECIFER (Wright et al. 2012). BLAST analysis was performed to confirm the identity of the isolates, and a NJ tree constructed to determine their positions within previously defined Frankia clusters (Normand et al. 1996). Bootstrap values are expressed as percentages and were determined from 1000 replicates (Felsenstein 1985).

\section{Results}

Using the Frankia nitrogenase-specific primer pair nifHf1/nifHr, PCR products of the expected size (641 bp) were obtained from 202 of 210 (96\%) Morella nodule lobe extracts, collected from natural stands of all six species of Morella examined (Table 2). Nodules in which nifH sequences could not be detected were collected from $M$. kraussiana on the northern plateau of Table Mountain exclusively (not indicated in Figure 1). These nodules were subsequently tested for the presence of cluster II Frankia nifH sequences, which were also found to be absent (results not shown). Following this, nodules from this site were not further investigated.

Sequence analysis revealed the presence of twenty-six non-identical 606 bp nifH sequences (CFN 1 to 26). Average similarity between non-identical Cape frankiae nifH sequences CFN1-CFN26 was 95.25\% (SD 0.021) and cluster analysis in 
Table 2: Occurrence of 606 bp nifH sequences in nodules of Cape Morella species. Sequences are listed by Cape Cluster genotype, defined at $>97 \%$ similarity, then by prevalence. In-silico translation products are indicated, as are Frankia isolates corresponding to nodule derived nifH sequences. CC-1 and CC-2 correspond to cluster I Frankia (AlnusHIG). CC-3 to CC-7 correspond to cluster III Frankia (Elaeagnus-HIG).

\begin{tabular}{|c|c|c|c|c|c|c|c|c|c|c|}
\hline 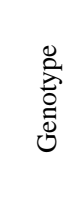 & 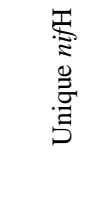 & 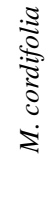 & 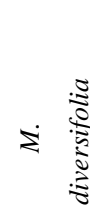 & 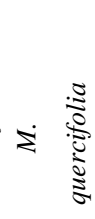 & 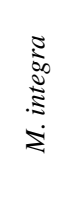 & 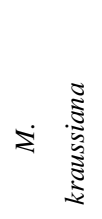 & 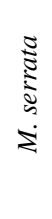 & స్ & 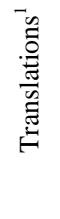 & $\begin{array}{l}\text { 岕 } \\
\frac{\pi}{0} \\
0 \\
0\end{array}$ \\
\hline \multirow{5}{*}{$\mathrm{CC}-1$} & CFN1 & & & & 42 & & 6 & 48 & 1 & FMi1, FMi2 \\
\hline & CFN3 & & 7 & 1 & 2 & 6 & & 16 & 1 & FMk1, FMq1 \\
\hline & CFN20 & & & & 1 & & & 1 & 1 & \\
\hline & CFN22 & & & & 1 & & & 1 & 1 & \\
\hline & CFN23 & & & & 1 & & & 1 & 1 & \\
\hline \multirow{2}{*}{$\mathrm{CC}-2$} & CFN10 & & 6 & & & & & 6 & 2 & \\
\hline & CFN16 & & 2 & & & & & 2 & 2 & \\
\hline \multirow{10}{*}{$\mathrm{CC}-3$} & CFN5 & 12 & & 1 & & & & 13 & $3 a$ & FMc1, FMc2, FMc3 \\
\hline & CFN6 & 11 & 2 & 6 & & & & 19 & $3 b$ & \\
\hline & CFN7 & 6 & & 2 & 4 & & & 12 & $3 b$ & \\
\hline & CFN8 & & 9 & & & & & 9 & $3 b$ & \\
\hline & CFN9 & 8 & & & & & & 8 & $3 b$ & FMc4 \\
\hline & CFN11 & & & 4 & & & & 4 & $3 b$ & \\
\hline & CFN13 & 4 & & & & & & 4 & $3 b$ & \\
\hline & CFN14 & & & 2 & & & & 2 & $3 b$ & FMc5 \\
\hline & CFN17 & 2 & & & & & & 2 & $3 b$ & \\
\hline & CFN26 & 1 & & & & & & 1 & $3 b$ & \\
\hline \multirow{6}{*}{ CC-4 } & CFN2 & 20 & & & & & & 20 & 4 & FMc6, FMc7 \\
\hline & CFN4 & & & 20 & & & & 20 & 4 & \\
\hline & CFN18 & 2 & & & & & & 2 & 4 & \\
\hline & CFN19 & & & 1 & & & & 1 & 4 & \\
\hline & CFN21 & & & & 1 & & & 1 & 4 & \\
\hline & CFN25 & 1 & & & & & & 1 & 4 & \\
\hline $\mathrm{CC}-5$ & CFN12 & & 4 & & & & & 4 & 5 & \\
\hline CC-6 & CFN15 & & 1 & 2 & & & & 3 & 6 & \\
\hline $\mathrm{CC}-7$ & CFN24 & 1 & & & & & & 1 & 7 & \\
\hline Total & & 68 & 31 & 39 & 52 & 6 & 6 & 202 & & \\
\hline
\end{tabular}

${ }^{1}$ In-silico translation of 606-bp fragments numbered to indicate identical translation products.

MOTHUR assigned all CFNs to one cluster at $\geq 92 \%$ identity. At $97 \%$ sequence similarity, CFNs grouped into a total of seven Frankia genotypes, which are hereafter referred to as $\underline{\text { Cape }} \underline{\text { Clades }}$ (CC) 1 to 7 . In silico translations of the twenty-six nonidentical 606 bp CFNs revealed identical peptide sequences within each CC, with the sole exception of CFN5 whose translation product differed from the rest of CC-3 at one position (Table 2).

NCBI nucleotide BLAST identified all twenty-six unique $606 \mathrm{bp}$ amplicons as Frankia nitrogenase reductases (nifH). Phylogenetic analysis of these sequences, trimmed to $512 \mathrm{bp}$, clearly assigned nif $\mathrm{H}$ sequences recovered in this study to either 
cluster I (the Alnus-HIG) or cluster III (the Elaeagnus-HIG), with Neighbor joining, Maximum likelihood, Maximum parsimony and Bayesian analysis of the $512 \mathrm{bp}$ nif $\mathrm{H}$ alignment producing similar tree topologies (Figures $2 \& 3$ ).

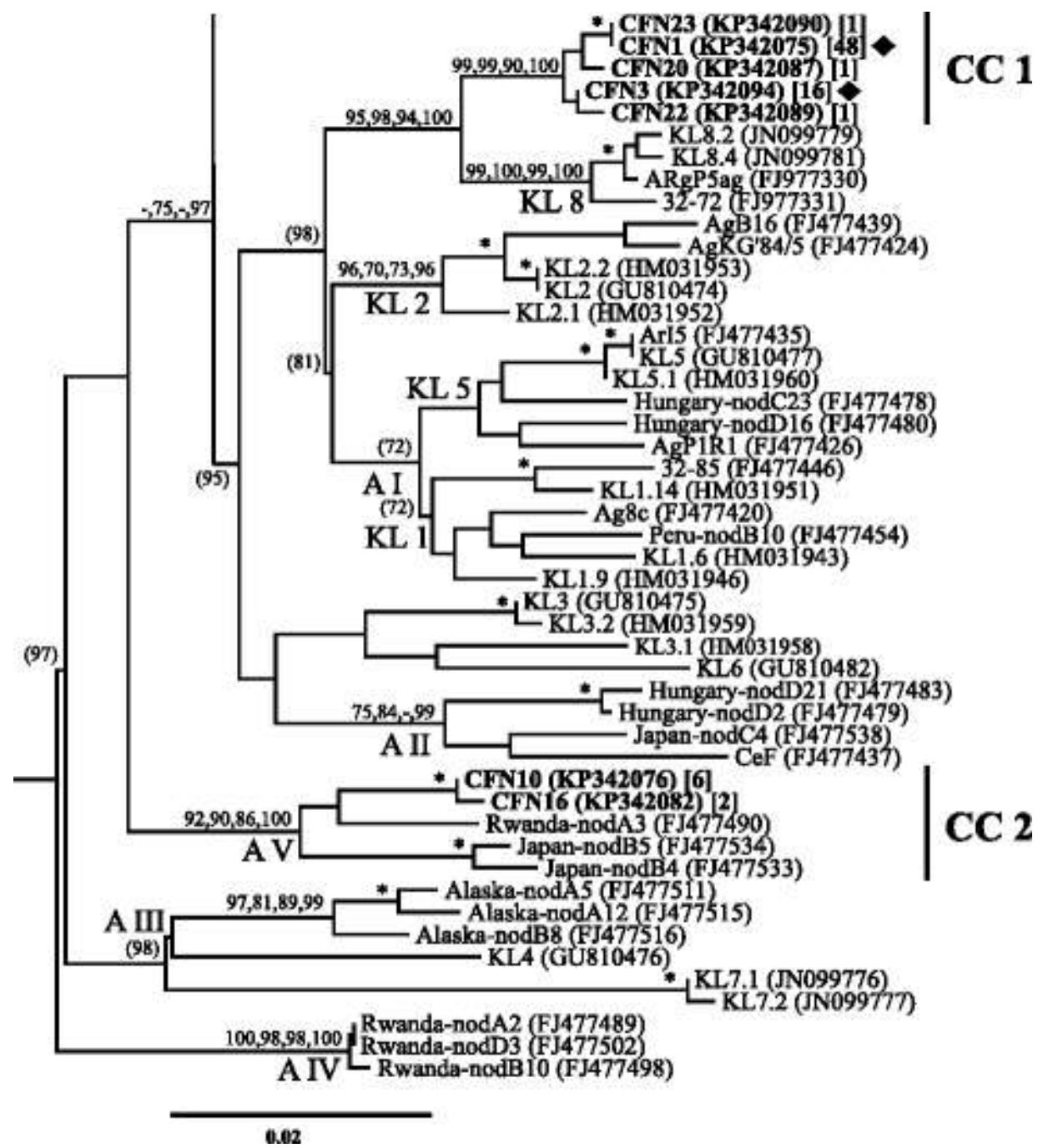

Figure 2: Phylogenetic tree generated using 512 bp nifH gene sequences from Frankia isolates and nodule-derived sequences, cut to display sequences from cluster I (the Alnus host infection group) only. Sequences are labelled with country of origin, genotype name or strain designation and GenBank accession number. Sequences encountered in this study are designated in bold, with GenBank accession numbers indicated in brackets followed by the number of nodules in which each sequence was detected. Diamonds indicate Cape Frankia isolates corresponding to nodule-derived nifH sequences. Numbers at nodes reflect bootstrap (BS) measures from neighbour joining, maximum likelihood and maximum parsimony analyses, and posterior probabilities (PP) from Bayesian analysis, respectively. Only values above $70 \%$ are shown. Where nodes were supported by Bayesian analysis only, PP values are indicated in parentheses. Asterisks indicate terminal nodes with support from at least 3 of the 4 phylogenetic methods. Frankia Alnus sub-groups AI-AV (Welsh et al. 2009a), KL1-5 and KL6-8 (Kennedy et al. 2010; Higgins and Kennedy 2012) are labelled where appropriate, and Cape clusters (CC) are indicated. An uncultured Frankia strain from Datisca nodules (X76398) was included as the outgroup (not shown). 


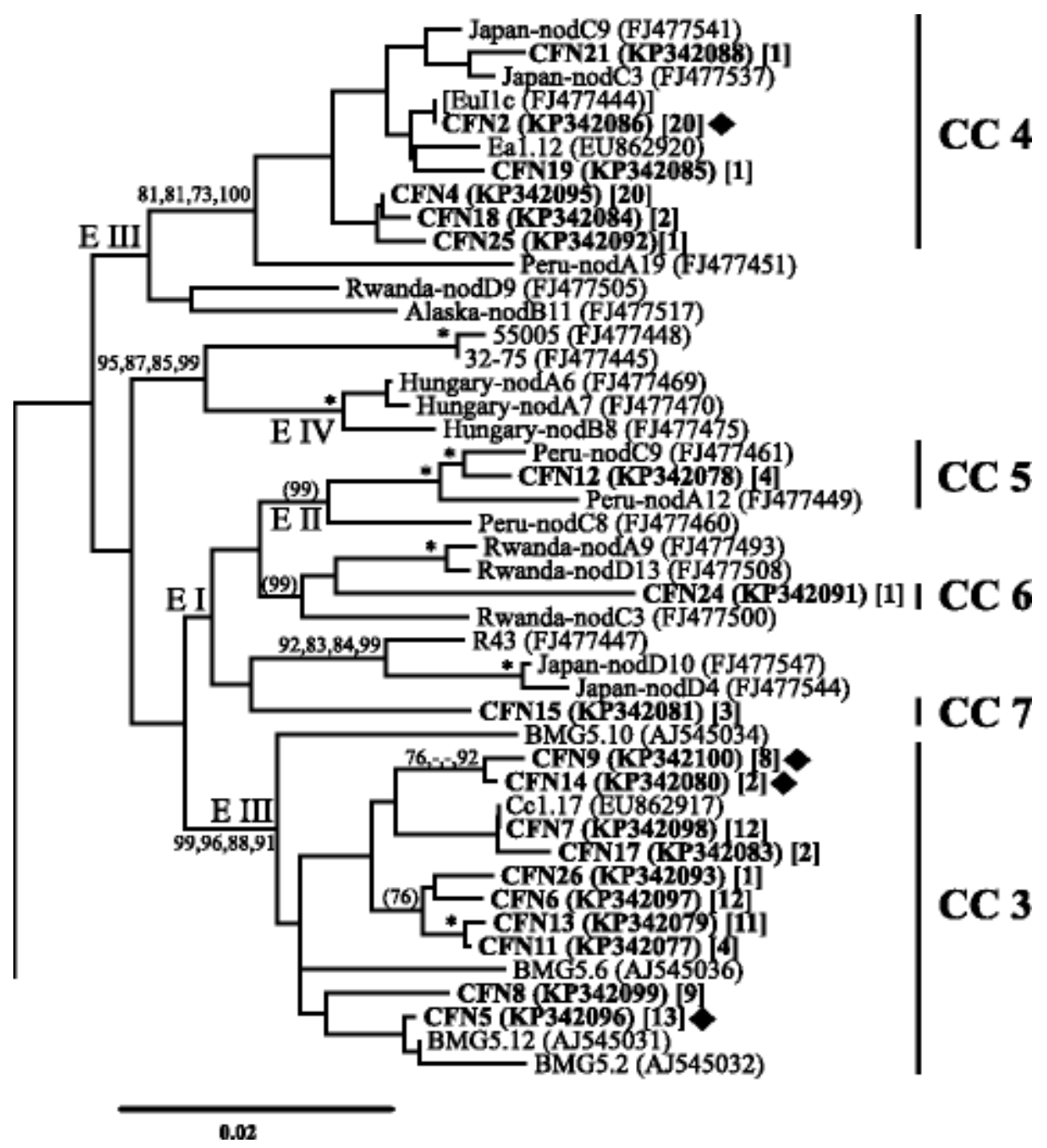

Figure 3: Phylogenetic tree generated using 512 bp nifH gene sequences from Frankia isolates and nodule-derived sequences, cut to display sequences from cluster III (the Elaeagnus host infection group) only. Sequences are labelled with country of origin, strain designation and GenBank accession number. Sequences encountered in this study are designated in bold, with Genbank accession numbers indicated in brackets followed by the number of nodules in which each sequence was detected. Diamonds indicate nodule-derived nifH sequences corresponding to Cape Frankia isolates. Numbers at nodes are bootstrap (BS) measures from neighbour joining, maximum likelihood and maximum parsimony analysis, and posterior probabilities (PP) from Bayesian analysis, respectively. Only values above 70\% are shown. Where nodes were supported by Bayesian analysis only, PP values are indicated in parentheses. Asterisks indicate terminal nodes with support from at least 3 of the 4 phylogenetic methods. Elaeagnus clusters EI-EIV (Welsh et al. 2009a) are labelled, and Cape clusters (CC) are indicated on the right. EUI1c's nifH sequence (bracketed) is aberrant as the gene is now known to be absent from this strain's genome (NC_014666). An uncultured Frankia strain from Datisca nodules (X76398) was included as the outgroup (not shown).

Two of the seven CC genotypes were assigned to Frankia cluster I, and the remaining five to cluster III (Table 2, Figures $2 \& 3$ ). The dominant genotypes (CC-1, CC-3 and CC-4) were found in 186 of 202 nodules (92\%) and totaled 67, 74 and 45 nodules per clade, respectively. Three of the cluster III genotypes (CC-5, CC-6, CC7) were represented by single non-identical sequences only.

Within the Alnus HIG, genotype CC-2 belonged to subgroup AV, as defined by Welsh et al. (2009a). Genotype CC-1 is novel to our study and is most closely related 
to KL8, described by Kennedy et al. (2010). Within the Elaeagnus HIG the majority of sequences (119/127) fell within EIII, previously described by (Welsh et al. 2009a). The remaining 8 sequences comprised genotypes clustering within EI (CC-6, CC-7) and EII (CC-5).

Ten clonally pure Frankia strains, representing each of the numerically dominant CC genotypes found in the nodules (CC-1, CC-3 and CC-4), were successfully isolated from nodules of M. cordifolia (FMc1-FMc6), M. integra (FMi1, FMi2), M. kraussiana (FMk1) and M. quercifolia (FMq1) (Table 2, Figure 4). In each case nif $\mathrm{H}$ sequences from the isolates were identical to those found in the nodules of the host species from which they were isolated (Table 2). In each case 16S rRNA BLAST analysis confirmed the identity of the isolates as Frankia, and phylogenetic analysis assigned them to the same HIGs indicated by nifH analysis (Figure 4).

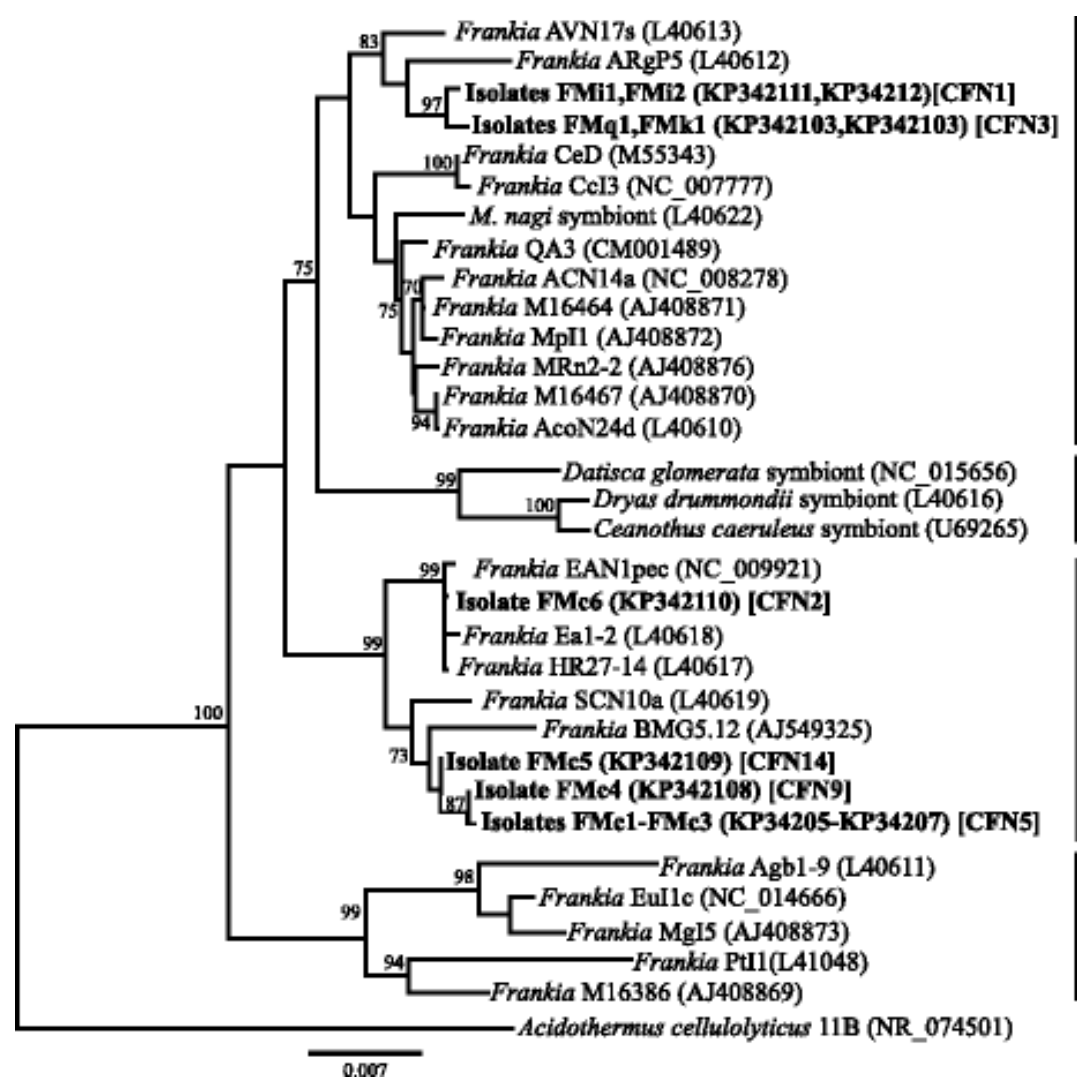

\section{Cluster I \\ Alnus/Casuarinal Myrica/Morella}

\section{Cluster II}

Datisca/Dryas/Ceanothus

Cluster III

Elaeagnus/Morella

\section{Cluster IV}

Nod(-) and/or Fix(-)

Figure 4: Neighbour-joining phylogenetic tree of 1428 bp partial 16S ribosomal RNA gene sequences showing positions of Frankia strains within clusters according to Normand et al. (1996). Isolates are labeled with trivial designations and GenBank accession number. Cape isolates are indicated in bold, with trivial strain designation, GenBank accession number and their corresponding nif $\mathrm{H}$ sequence. Uncultivated strains are indicated by the name of the host plant species. Accession numbers are shown in parentheses; Frankia clusters are indicated in the margin. Acidothermus cellulolyticus $11 \mathrm{~B}$ was included as outgroup.

\section{Discussion}

Frankiae nifH sequences were recovered from the majority of nodules collected in 
this study. From 202 successful PCR reactions, a total of 26 unique $606 \mathrm{bp}$ nifH sequences were obtained, all of which were identified as Frankia nitrogenase reductases by BLAST analysis (Table 2). A $\geq 97 \%$ similarity threshold is commonly used to describe Frankia diversity as it allows for differentiation between cluster I and cluster III strains, with reliable assignment to sub-clusters within these groups (Higgins and Kennedy 2012; Welsh et ala 2009a; Mirza et al 2009; Lipus and Kennedy 2011). When Cape Frankia nifH sequences were clustered at $\geq 97 \%$ similarity a total of seven genotypes were found, namely (CC) 1 to 7 (Table 2).

Two of these genotypes were assigned to cluster I and the remaining five CC's to cluster III (Table 2). Both major Frankia host infection groups are therefore associated with Cape Morella in their natural habitats. The overall number of detected strains (26) was comparatively low, which is in keeping with what has been found in other environments (Huguet et al. 2001; Welsh et al. 2009a; Vanden Heuvel et al. 2004; Pokharel et al. 2011).

In order to determine the position of Cape nodular nif $\mathrm{H}$ sequences in relation to previously described Frankia, CFNs were aligned with Frankia nifH sequences from public databases. As many database sequences are incomplete, the alignment was trimmed to $512 \mathrm{bp}$ to allow the incorporation of the greatest number of sequences possible. Following trimming the number of unique Cape Morella derived sequences was reduced from 26 to 25, as CFN1 and CFN23 are identical across the remaining alignment positions. CFN cluster assignments at a $\geq 97 \%$ identity threshold for the $512 \mathrm{bp}$ truncations were identical to those found for the 606 bp sequences.

When different phylogenetic treeing methods have previously been applied to Frankia nif $\mathrm{H}$ sequences, similar tree topologies have been found irrespective of the methodology used (Welsh et al 2009a). Sub-clusters within these trees were assigned primarily based on tree topology and node support measures rather than a strict sequence similarity threshold. Consequently, clusters outlined by (Welsh et al. 2009a) are defined at a range of similarity values from $93 \%$ to $99 \%$. It is known that defined similarity values (or OTU assignments) for both nifH and 16S rRNA gene sequences, as well as other commonly used markers, do not necessarily agree with Frankia genospecies as defined in DNA/DNA hybridization and AFLP studies (Fernandez et al. 1989; Welsh et al. 2009a; Bautista et al. 2011). In line with this, the common practice of assigning microbial genetic marker sequences (usually 16S rDNA) to operational taxonomic units at defined thresholds has been criticized, principally because of the lack of support from an underlying theory of microbial speciation $\left(\right.$ Gevers et al. 2005) ${ }^{2}$.

Nevertheless, cut-offs of $97 \%$ similarity for nifH sequences are still commonly

${ }^{2}$ In one study nifH OTUs defined at 99.2 to $99.4 \%$ similarity were found to be ecologically meaningful in the grouping of Alnus-associated Frankia on a global scale (Sergei et al. 2014). 
used in investigations of Frankia diversity (Higgins and Kennedy 2012), and we found that in-silico translation of CFN sequences resulted in identical peptide sequences for nucleotide sequences within CC genotypes. Furthermore, peptide sequences were unique for each of the seven CC genotypes (Table 2). This finding supports the use of a $3 \%$ nucleotide dissimilarity threshold in cluster assignment for investigating Frankia diversity within the Cape region.

Identical nifH sequences were found in nodules from geographically distant sites, with eight of the thirteen general localities sharing identical CFNs with between one and three other locations (data not shown). Of the 26 non-identical nifH sequences, five (consisting of totals of 64 individual sequences from CC-1, and 44 from CC-3) were found at multiple sampling sites. In terms of host specificity, Frankia from both clusters I and III were represented in nodules from three of the six species examined (M. integra, M. diversifolia and M. quercifolia).

Cluster I sequences displayed low local diversity, a finding often encountered in studies of this host infection group (Huguet et al. 2001; Welsh et al. 2009b; Kennedy et al. 2010). Cluster I strains are typically associated with specific hosts, as demonstrated in sympatric Alnus stands, and where Alnus and Myrica gale grow together (Huguet et al. 2001; Pokharel et al. 2011). Furthermore, strains specifically infective on Myrica gale in Europe and North America display evidence of divergence, supporting the hypothesis that some degree of co-evolution exists between Frankia from this cluster and their hosts (Huguet et al. 2001; Huguet et al. 2004). While cluster I strains are cosmopolitan, local dominance by sub-groups within the cluster found in other studies and the presence of only two specific groups (CC-1 and CC-2) within the Cape region is evidence for greater selectivity between strains from this cluster and their hosts than is found with cluster III strains.

Within cluster I sequences from genotype CC-1 were numerically dominant, with five unique sequences recovered from a total of 67 nodules, derived from five Morella species at geographically dispersed sites. While soil conditions were not determined for all study sites, cluster I sequences were found in nodules from acidic soils exclusively (Table 1), and were dominant in M. integra collected at riparian sites in the Cederberg mountains (Figure 1, site A2). Sequence CFN1 was also detected in six nodules from M. serrata (Figure 1, site 6B) where this species inhabits a similar riparian habitat. Sequence $\mathrm{CFN} 3$ was detected in nodules from riparian $M$. integra, as well as nodules from $M$. diversifolia, M. quercifolia and M. kraussiana, all from montane habitats on the Table Mountain range.

According to both cluster and phylogenetic treeing analyses, $\mathrm{CC}-1$ is a sister group to genotype KL8, recently described from four Alnus nodules collected in Mexico (Higgins and Kennedy 2012). Nodules from a M. serrata stand on the banks of the Eerste river (site B6) harbored sequence CFN1, identical to those dominant in $M$. integra nodules collected at riparian sites in the Cederberg mountains (Figure 1, site A3), exclusively. Similarly, sequence CFR2 was found in M. kraussiana, M. 
diversifolia and M. quercifolia nodules from acidic soils on Table Mountain, as well as M. integra nodules collected in the Cederberg (Figure 1, site A3). Myrica gale is known to be nodulated by cluster I strains exclusively in its natural habitats, where soils are typically acidic and water-logged (Clawson and Benson 1999), similar to the soil in which $M$. integra grew.

Cluster III strains were more diverse, with 18 unique sequences from five Cape clusters distributed amongst three of the four clusters identified by (Welsh et al. 2009a). Within cluster III sequences CFN5 and CFN6, the most abundant sequences in this cluster, were found at sites with the highest degree of geographical separation, indicating cosmopolitan distribution for strains from this cluster within the region. Similarly, cluster I sequences CFN1 and CFN3 were found in all montane areas surveyed, ranging from the Boland and Table Mountain ranges in the south to the Cederberg range in the north. As with the cluster I sequences, unique genotypes were associated with $M$. diversifolia at site B1 (Figure 1) exclusively, and were found in numerous nodules. In our analysis sub-cluster EIII was resolved into two separate groups (CC-3 and CC-4), with CFN sequences present in both. Genotypes CC-2, CC5 and CC-6 were detected in $M$. diversifolia nodules only.

This last species is restricted to the mountains of the Cape peninsula (Goldblatt and Manning 2000; Helme and Trinder-Smith 2006) and it is possible that these genotypes are associated uniquely with it. More intensive sampling would be necessary to establish whether specific relationships between these Frankia genotypes and $M$. diversifolia exist. Furthermore, cluster III sequence CFN8 was found in this species which, while belonging to CC-3, was not detected in the nodules of any other host species. Assuming host/symbiont co-evolution Alnuscluster nifH sequences from CC-2 may therefore originate from Frankia evolving towards a preference for this host, and further investigation is warranted. No isolates from genotype AV are known to exist (Welsh et al. 2009a) and despite intense effort we were unable to isolate Frankia strains representing genotype CC-2.

Soil $\mathrm{pH}$ and other edaphic factors are known to influence both strain presence in nodules and the degree of nodulation (Smolander 1990; Zitzer and Dawson 1992; Dawson and Klemp 1987). For example, soil pH had clear effects on nodulation of Alnus glutinosa and Elaeagnus angustifolia species in greenhouse trials, with the former more heavily nodulated at lower, and the latter at higher, pH's (Zitzer and Dawson 1992). In our study $M$. cordifolia was found in neutral to alkaline coastal soils (Table 1, Figure 1), was the most widely and intensively sampled host species with 67 nodules recovered from 5 geographically widely-dispersed coastal sites, accounting for 11 of 26 unique CFNs (Table 2), and was nodulated by cluster III strains exclusively. Similarly, M. quercifolia was nodulated by cluster III strains exclusively when sampled at sites with alkaline soils. A single $M$. quercifolia nodule recovered from soil at site B3 (Figure 1) yielded a cluster I sequence (CFN3), indicating that this species too is promiscuous in the field. This sample was recovered from similar 
soil to that of M. kraussiana at the same site, for which soil $\mathrm{pH}$ was found to be acidic (Table 1). This supports suggestions that soil $\mathrm{pH}$ may play a determining role in Frankia strain selection (Huguet et al. 2001).

Welsh et al. (2009a) found local dominance in soils collected from 5 globally distributed sites, with Frankia clusters present in any one soil rarely detected in others. Our findings mirror this, as sequences from cluster EIII from the Elaeagnus HIG were dominant in Cape Morella nodules, with sequences assigned to clusters EI and EII only rarely detected. Similarly, Cape sequences assigned to the Alnus HIG were limited to two sub-clusters only, namely Welsh's cluster AV and a new cluster: CC-1.

Higgins and Kennedy (2012) reported a new Frankia nifH lineage (KL8) in their survey of Alnus nodules across North America. In our analysis Frankia isolates ARgP5ag and 32-72 (which were excluded from their analysis) clustered within this genotype and separately from $\mathrm{CC}-1$, at $97 \%$ sequence identity and with good support from all four treeing methods (Figure 2). ARgP5ag is currently the sole member of Frankia genospecies G3 (Fernandez et al 1989; Bautista et al. 2011). With a average nifH similarity of only $96.8 \%$ to KL8, the previously described Frankia cluster most similar to it, Cape Frankia genotype CC-1 may comprise a new group of Frankia within the otherwise well-described cluster I.

Notably, we did not detect strains clustering with Casuarina genotypes (nif $\mathrm{H}$ subgroup AII) in our survey. Morella is the only extant actinorhizal genus native to southern Africa, as endemic Casuarina became extinct in the middle Miocene (Coetzee and Praglowski 1984; Linder 2003). This study thus provides additional support for the claim that Morella do not serve as a reservoir for typical Casuarina strains in the absence of their normal hosts (Simonet et al.1999).

While Frankia strains have been previously isolated from indigenous African actinorhizal hosts, they have never been obtained from species endemic to the continent (Gtari et al. 2004; Gomaa et al. 2008). Of the six Morella investigated in this study, we isolated a total of ten strains from four host species (Table 2). Nearcomplete $16 \mathrm{~S}$ and partial nif $\mathrm{H}$ gene fragments were obtained from ten Frankia isolates, and all isolate-derived nif $\mathrm{H}$ sequences corresponded to sequences obtained from nodules (Figure 4). These strains displayed typical Frankia phenotypes, including slow growth rates, diazovesicle formation and multilocular sporangia (Whitman et al. 2012). Isolates from M. quercifolia and M. kraussiana were identical in terms of their nif $\mathrm{H}$ and 16S rRNA gene sequences. The nodules from which they were isolated were collected at the same site (Figure 1, site B3) and it is thus possible that they are the same strain. Frankia strains FMc1, FMc2 and FMc3 had identical $16 \mathrm{~S}$ and nif $\mathrm{H}$ sequences, but displayed significant phenotypic variation, including distinct differences in pigment production, substrate utilization and sporulation intensity (Wilcox, unpublished data). Previous studies have reported that phenotypically distinct isolates may have identical marker sequences (Bern'echeD’Amours et al. 2011). 
Root nodules have previously been found to be formed on actinorhizal hosts by atypical cluster IV Frankia, which would not be detected with the described methodology, and other actinomycetes found in actinorhizal nodules may be involved in their induction (Valdes et al. 2005; Gtari et al. 2012; Carro et al. 2013). In addition to this, nitrogen-fixing actinomycetes other than Frankia have previously been isolated from actinorhizal nodules (Valdes et al. 2005) and a Frankia nifH sequence has recently been found in a non-Frankia actinomycete (BMG5.6) isolated from Elaeagnus nodules from Tunisia (Gtari et al. 2004). For this reason, nodule derived nif $\mathrm{H}$ sequences by themselves do not guarantee the identity of nodular microsymbionts as Frankia, just as root nodules on actinorhizal plant roots do not guarantee the presence of Frankia. Our Frankia isolates have identical 606 bp nifH sequences to the numerically dominant nodular sequences in genotypes CC-1, CC-3 and CC-4, as well as two less abundant sequences from CC-3 (Table 2). These represent a majority of nodular sequences recovered in the study (111 of 202). The isolation of nodule endophytes, their characteristic cell morphologies, and confirmation of their identity by $16 \mathrm{~S}$ rRNA and nif $\mathrm{H}$ sequencing, strongly supports the conclusion that Cape Morella microsymbionts detected in the current survey of nodular nifH sequences are indeed Frankia.

Cape cluster I Frankia have, following the local extinction of Casuarina, nodulated Morella exclusively and it will be interesting to deter- mine whether they are infective/effective on "traditional" cluster I hosts from the Betulaceae and Casuarinaceae. As representatives of this cluster are included among our isolates, future genomic comparison and cross-inoculation studies with Alnus, Casuarina and hosts from the Myricaceae will provide a deeper understanding of Frankia host specificity, genome evolution and the molecular mechanisms of infection for these strains.

The influence of geographic location on Frankia occurrence was not investigated in depth as it could not be detached from various potentially confounding factors, which included the limited number of populations sampled for most host species (particularly M. serrata and M. kraussiana), and varying soil conditions between sites.

\section{Conclusions}

Southern African actinorhizal hosts of the genus Morella are nodulated by Frankia from both cluster I (Alnus-infective) and cluster III (Elaeagnus -infective) under natural field conditions. Within Africa the diversity of Frankia infective on endemic Morella species had previously not been investigated. Morella of the Cape flora are promiscuous in the field, with sequences from cluster I and cluster III recovered from nodules of three of the six species sampled. Cluster I strains were represented by seven unique sequences in two genotypes, assigned to AV and a new sub-cluster closely related to KL8. Cluster III strains were more diverse, with a total of 18 unique sequence distributed across five 
genotypes within previously described groups. Three Morella species (M. integra, M. diversifolia and $M$. quercifolia) were found to be promiscuous in the field. Two ( $M$. serrata, M. kraussiana) were nodulated by cluster I strains while M. cordifolia was nodulated by cluster III strains exclusively. Morella displayed an apparent preference for cluster I strains under acidic soils conditions, with these strains completely absent in nodules recovered from neutral or alkaline soils. Ten Frankia strains representing six non-identical nifH sequences, two from a single cluster I genotype (CC-1), four from two cluster III genotypes (CC-3 and CC-4). This work constitutes the first investigation into the diversity of Frankia infective on endemic actinorhizal plant species of southern Africa, and reports the first isolation of Frankia strains from African Morella.

\section{Acknowledgements}

The authors sincerely thank the staff of SANParks, Cape Nature, and the Cape Flats and Zandvlei nature reserves, and gratefully acknowledge the South African National Research Foundation and University of Pretoria Genomics Research Institute for financial support. R Knight is thanked for advice on locating Morella in the field. T Genade, A de Groot, JL de Klerk, G Theron, MJ Vismer and W Williams assisted with field work. T Genade critically reviewed the manuscript.

\section{List of references}

Bassi CA, Benson DR (2007) Growth characteristics of the slow-growing actinobacterium Frankia sp. strain cci3 on solid media. Physiol Plant 130:391-399

Bautista GHH, Cruz HA, Nesme X, Valdes M, Mendoza HA, Fernandez MP (2011) Genomospecies identification and phylogenomic relevance of AFLP analysis of isolated and non-isolated strains of Frankia spp. Syst Appl Microbiol 34:200-206

Benson DR, Dawson JO (2007) Recent advances in the biogeography and genecology of symbiotic Frankia and its host plants. Physiol Plant 130(3):318-330

Benson DR, Vanden Heuvel BD, Potter D (2004) Actinorhizal symbioses: diversity and biogeography. In: Gillings M (ed) Plant Microbiology, BIOS Scientific Publishers Ltd., Oxford

Bern`eche-D’Amours A, Ghinet MG, Beaudin J, Brzezinski R, Roy S (2011) Sequence analysis of rpoB and rpoD gene fragments reveals the phylogenetic diversity of actinobacteria of genus Frankia. Can J Microbiol 57:244-249

Bond G (1971) Fixation of nitrogen in two African species of Myrica. New Phytol 70:18

Bond G (1976) The results of the IBP survey of non-legume root nodules formation in non-leguminous angiosperms. In: Nutman PS (ed) Symbiotic Nitrogen Fixation in Plants, Cambridge Univ. Press, pp 443-474 
Callaham D, Del Tridici P, Torrey JG (1978) Isolation and cultivation in vitro of the actinomycete causing root nodulation in Comptonia. Science 199:899-902

Carro L, Pujic P, Trujillo ME, Normand P (2013) Micromonospora is a normal occupant of actinorhizal nodules. J Biosci 38(4):685-693

Clawson ML, Benson DR (1999) Natural diversity of Frankia strains in actinorhizal root nodules from promiscuous hosts in the family Myricaceae. Appl Environ Microbiol 65(10):4521-4527

Clawson ML, Gawronski J, Benson DR (1999) Dominance of Frankia strains in stands of Alnus incana subsp. rugosa and Myrica pensylvanica. Can J Botany 77:1203-1207, 11111

Coetzee JA, Praglowski J (1984) Pollen evidence for the occurrence of Casuarina and Myrica in the Tertiary of South Africa. Grana 23(1):23-41

Darriba D, Taboada GL, Doallo R, Posada D (2012) jModelTest 2: more models, new heuristics and parallel computing. Nat Methods 9:772

Dawson JO, Klemp MT (1987) Proceedings Central Hardwoods Forest Conference VI. In: Variation in the capacity of Black Alder to nodulate in central Illinois soils, Dept. Forestry, Univ. Tenn., Knoxville, TN, pp 255-260

Felsenstein J (1985) Confidence limits on phylogenies: an approach using the bootstrap. Evolution 39(4):783-791

Fernandez MP, Meugnier H, Grimont PAD, Bardin R (1989) Deoxyribonucleic acid relatedness among members of the genus Frankia. Intl J Syst Evol Micr 39(4):424429

Gevers D, Cohan FM, Lawrence JG, Spratt BG, Coenye T, Feil EJ, Stackebrandt E, Van De Peer Y, Vandamme P, Thompson FL, Swings J (2005) Re-evaluating prokaryotic species. Nat Rev Microbiol 3:733-739

Goldblatt P (1978) An analysis of the flora of southern Africa: its characteristics, relationships, and origins. Ann Missouri Bot 65(2):369-436

Goldblatt P, Manning JC (2000) Cape Plants. A conspectus of the Cape flora of South Africa. National Botanical Institute of South Africa. pp. 547

Gomaa AM, Abo-Aba SEM, Awad NS (2008) Isolation, characterization and genetic differentiation of Frankia sp. isolated from ecologically different Egyptian locations. Res J Cell Mol Biol 2(1):6-17

Gtari M, Dawson JO (2011) An overview of actinorhizal plants in Africa. Func Plant Biol 38:653-661

Gtari M, Brusetti L, Skander G, Mora D, Boudabous A, Daffonchio D (2004) Isolation of Elaeagnus-compatible Frankia from soils collected in Tunisia. FEMS Microbiol Lett 234:349-355

Gtari M, Ghodhbane-Gtari F, Nouioui I, Beauchemin NJ, Tisa LS (2012) Phylogenetic perspectives of nitrogen-fixing actinobacteria. Arch Microbiol 194:311 
Guindon S, Gascuel O (2003) A simple, fast and accurate method to estimate large phylogenies by maximum-likelihood. Syst Biology 52:696-704

He XH, Chen LG, Hu XQ, Asghar S (2004) Natural diversity of nodular microsymbionts of Myrica rubra. Plant Soil 262:229-239

Helme N, Trinder-Smith T (2006) The endemic flora of the Cape Peninsula, South Africa. S Afr J Bot 72:205-210

Herbert J (2005) Systematics and biogeography of Myricaceae. Dissertation, University of St. Andrews

Higgins LM, Kennedy PG (2012) Symbiotic Frankia bacteria in Alnus forests in the United States of America: is geographic location a good predictor of assemblage structure? Botany 90:423-431

Huguet V, McCray Batzli J, Zimpfer JF, Normand P, Dawson JO, Fernandez MP (2001) Diversity and specificity of Frankia strains in nodules of sympatric Myrica gale, Alnus incana, and Sheperdia canadensis determined by rrs gene polymorphism. Appl Environ Microbiol 67(5):2116-2122

Huguet V, Mergeay M, Cervantes E, Fernandez MP (2004) Diversity of Frankia strains associated to Myrica gale in western Europe: impact of host plant (Myrica vs. Alnus) and of edaphic factors. Environ Microbiol 6(10):1032-1041

Huguet V, Ojeda Land E, Garcia Casanova J, Zimpfer JF, Fernandez MP (2005) Microbial diversity of microsymbionts from the relict species Myrica rivas-myrica faya (Ait.) and Martinezii (S.) in Canary Islands and Hawaii. Microbial Ecol 49(4):617-625

Kennedy PG, Weber MG, Bluhm AA (2010) Frankia bacteria in Alnus rubra forests: genetic diversity and determinants of assemblage structure. Plant Soil 335:479492

Lechevalier MP, Lechevalier HA (1990) Systematics, Isolation and Culture of Frankia. In: Schwintzer CR, Tjepkema JD (eds) The Biology of Frankia and Actinorhizal Plants, Academic Press, Inc., New York, N.Y., pp 35-60

Linder HP (2003) The radiation of the Cape flora, southern Africa. Biol Rev 78:597638

Lipus A, Kennedy PG (2011) Frankia assemblages associated with Alnus rubra and Alnus viridis are strongly influenced by host species identity. Int J Plant Sci 172(3):403-410

Maggia L, Bousquet J (1994) Molecular phylogeny of the actinorhizal Hamamelidae and relationships with host promiscuity towards Frankia. Mol Ecol 3:459-467

Meesters TM, van Genesen ST, Akkermans ADL (1985) Growth, acetylene reduction activity and localization of nitrogenase in relation to vesicle formation in Frankia strains Cc1.17 and Cp1.2. Arch Microbiol 143:137-142

Miller MA, Pfeiffer W, Schwartz T (14 Nov. 2010) Creating the CIPRES Science Gateway for Inference of Large Phylogenetic Trees. Proceedings of the Gateway Computing Environments Workshop (GCE), New Orleans, LA pp 1-8 
Mirza BS, Welsh A, Rieder JP, Paschke MW, Hahn D (2009) Diversity of frankiae in soils from five continents. Syst Appl Microbiol 32:558-570

Normand P, Orso S, Cournoyer B, Jeannin P, Chapelon C, Dawson J, Evtushenko L, Misra AK (1996) Molecular phylogeny of the genus Frankia and related genera and emendation of the family Frankiaceae. Int J Syst Bacteriol 46(1):1-9

Normand P, Benson DR, Berry AM, Tisa LS (2014) The Family Frankiaceae. In: Rosenberg E, DeLong EF, Lory S, Stackebrandt E, Thompson F (eds) The Prokaryotes, Springer-Verlag, Berlin Heidelberg, pp 339-356

Pokharel A, Mirza BS, Dawson JO, Hahn D (2011) Frankia populations in soil and root nodules of sympatrically grown Alnus taxa. Microb Ecol 61:92-100

Rambaut A (2009) Figtree v1.2.3. Institute of evolutionary biology, university of Edinburgh. http://tree.bio.ed.ac.uk/software/figtree

Schofield RK, Wormald Taylor A (1955) The measurement of soil pH. Soil Sci Soc Am J 19(2):164-167

Sen A, Daubin V, Abrouk D, Gifford I, Berry AM, Normand P (2014) The phylogeny of actinobacteria revisited in the light of complete genomes, the orders Frankiales and Micrococcales should be split into coherent entities. Proposal of Frankiales ord. nov., Geodermatophilales ord. nov., Acidothermales ord. nov. and Nakamurellales ord. nov. Int J Syst Evol Microbiol 4(11):3821-3832

Sergei P, Bahram M, Urmas K, Tendersoo L (2014) Global biogeography of Alnusassociated Frankia actinobacteria. New Phytol 204(4):979-988

Simonet P, Navarro E, Rouvier C, Reddell P, Zimpfer J, Dommergues Y, Bardin R, Combarro P, Hamelin J, Domenach aM, Gourbi ere F, Prin Y, Dawson JO, Normand P (1999) Co-evolution between Frankia populations and host plants in the family Casuarinaceae and consequent patterns of global dispersal. Environ Microbiol 1(6):525-533

Smolander A (1990) Frankia populations in soils under different tree species with special emphasis on soils under Betula pendula. Plant Soil 121:1-10

South African National Biodiversity Institute Integrated Biodiversity Information System (SIBIS) (2014) http://sibis.sanbi.org/

Stamatakis A (2006) RAxML-VI-HPC: maximum likelihood-based phylogenetic analyses with thousands of taxa and mixed models. Bioinformatics 22(21):26882690

Sukumaran J, Holder MT (2010) DendroPy: a Python library for phylogenetic computing. Bioinformatics 26:1569-1571

Swofford DL (2003) PAUP. Phylogenetic Analysis Using Parsimony (and Other Methods). Version 4, Sinauer Associates, Sunderland, Massachusetts

The Plant List, Version 11 (2014) www.theplantlist.org. Accessed 12 November 2015 
Torrey JG (1990) Cross-inoculation groups within Frankia and host-endosymbiont associations. In: Schwintzer CR, Tjepkema JD (eds) The Biology of Frankia and Actinorhizal Plants, Academic Press, Inc., New York, N.Y., pp 83-106

Valdes M, Perez N, Estrada-de los Santos P, Caballero-Mellado J, Pena-Cabriales JJ, Normand P, Hirsch PR (2005) Non-Frankia actinomycetes isolated from surfacesterilized roots of Casuarina equisetifolia fix nitrogen. Appl Environ Microbiol 71(1):460-466

Van Ryssen FWJ, Grobbelaar N (1970) The nodulating and nitrogen fixing ability of South African Myrica. S Afr JSci 66(1):22-25

Vanden Heuvel BD, Benson DR, Bortiri E, Potter D (2004) Low genetic diversity among Frankia spp. strains nodulating sympatric populations of actinorhizal species of Rosaceae, Ceanothus (Rhamnaceae) and Datisca glomerata (Datiscaceae) west of the Sierra Nevada (California). Can J Microbiol 50:989-1000

Vandenbosch KA, Torrey JG (1983) Host-endophyte interactions in effective and ineffective nodules induced by the endophyte of Myrica gale. Can J Bot 61:28982909

Welsh A, Mirza BS, Rieder JP, Paschke MW, Hahn D (2009a) Diversity of Frankiae in root nodules of Morella pensylvanica grown in soils from five continents. Syst Appl Microbiol 32:201-210

Welsh AK, Dawson JO, Gottfried GJ, Hahn D (2009b) Diversity of Frankia populations in root nodules of geographically isolated Arizona Alder trees in central Arizona (United States). Appl Environ Microbiol 75(21):6913-6918

Whitman WB, Parte A, Goodfellow M, Kampfer P, Busse HJ, Trujillo ME, Ludwig W, Suzuki K (2012) Bergey's Manual of Systematic Bacteriology: Volume 5: The Actinobacteria. v. 5, pts. 1-2, Springer

Wright ES, Yilmaz LS, Noguera DR (2012) DECIPHER, a search-based approach to chimera identification for $16 \mathrm{~S}$ rRNA sequences. Appl Environ Microbiol 78(3):717-725

Zimpfer JF, Kennedy GJ, Smyth CA, Hamelin J, Navarro E, JDawson JO (1999) Localization of Casuarina-infective Frankia near Casuarina cunninghamiana trees in Jamaica. Can J Botany 77(9):1248-1256

Zitzer SF, Dawson JO (1992) Soil properties and actinorhizal vegetation influence nodulation of Alnus glutinosa and Elaeagnus angustifolia by Frankia. Plant Soil 140:197-204 